\title{
Shared flowering phenology, insect pests, and pathogens among wild, weedy, and cultivated rice in the Mekong Delta, Vietnam: implications for transgenic rice
}

\author{
Michael B. COHEN ${ }^{1,2 *}$, Salvatore ARPAIA ${ }^{3}$, La Pham LAN ${ }^{4}$, Luong Minh $\mathrm{CHAU}^{5}$ and Allison A. SNOW \\ 1 International Rice Research Institute (IRRI), DAPO 7777, Metro Manila, Los Baños, Philippines \\ 2 Present address: 1164377 Ave, Edmonton AB T6G 0M4, Canada \\ 3 Italian National Agency for New Technologies, Energy and the Environment (ENEA) Research Centre Trisaia, S.S. 106 Jonica Km 419,5, \\ 75026 Rotondella (MT), Italy \\ ${ }^{4}$ Institute of Agricultural Sciences of South Vietnam, 121 Nguyen Binh Khiem, District \# 1, Ho Chi Minh City, Vietnam \\ 5 Cuu Long Delta Rice Research Institute, Omon, Cantho, Vietnam \\ 6 Department of Evolution, Ecology, and Organismal Biology, Ohio State University, Columbus OH 43210, USA
}

Many varieties of transgenic rice are under development in countries where wild and weedy relatives co-occur with the crop. To evaluate possible risks associated with pollen-mediated transgene dispersal, we conducted a two-year survey in Vietnam to examine overlapping flowering periods of rice (Oryza sativa L.), weedy rice (O. sativa), and wild rice ( $O$. rufipogon Griff.), all of which are inter-fertile. We surveyed populations in two regions of the Mekong Delta, northern and southern, and at three sites in each of three habitats per region: fresh water, saline water, and acid sulfate soil. Weedy rice frequently flowered simultaneously with neighboring cultivated rice plants. Flowering was more seasonal in wild rice and often peaked in November and December. Peak flowering times of wild rice overlapped with adjacent rice fields at all of the saline sites and half of the acid sulfate sites. The longer flowering season of wild rice ensured that crop-to-wild gene flow was possible in fresh water habitats as well. Our second objective was to determine whether wild and weedy rice populations are exposed to pests that could be targeted by future transgenes, which may then provide fitness benefits. These populations shared many pathogen and insect herbivore species with cultivated rice (leaffolder, locust, cricket, planthoppers, rice bug, stem borer, sheath blight, blast, bacterial leaf blight, and brown spot). Damage by leaffolders and locusts was the most frequently observed insect feeding damage on all three rice types. Indicator species analysis revealed that most of the insect herbivores were associated with particular habitats, demonstrating the importance of broad geographic sampling for transgenic rice risk assessment. These survey data and the strong likelihood of gene flow from cultivated rice suggest that further studies are needed to examine the effects of transgenic traits such as resistance to pests on the abundance of wild and weedy rice.

Keywords: Oryza sativa / risk assessment / crop-wild gene flow / introgression / insect herbivores / diseases / field survey / Vietnam / genetically modified / transgenic

\section{INTRODUCTION}

As one of the world's most important food crops, rice is the subject of intensive breeding programs utilizing conventional, marker-assisted, and transgenic techniques (Khush, 2001). Desirable traits for rice improvement include nutritional quality, yield, and abiotic and biotic stress tolerance. Many foreign genes have been transferred to rice by genetic engineering (e.g., Giri and Laxmi, 2002; Lu and Snow, 2005). Transgenic lines have

*Corresponding author: snow.1@osu.edu been field tested in China, India, the United States, and other countries, but are not widely grown (James, 2006). To date, the USA is the only country to have approved non-regulated cultivation of a transgenic rice (AgBios, 2007). Delays in release of transgenic rice cultivars are due in part to concerns about biosafety and international trade.

One of the major biosafety concerns pertaining to the environmental release of genetically engineered crops is related to transgene outcrossing to wild and weedy relatives (Ellstrand, 2003), an issue of particular relevance to rice. Transgenes are typically inherited as dominant traits 
that result from strong, constitutive gene expression, with the potential to have major effects on plant fitness (e.g., Snow et al., 2003). The evaluation of biosafety risks must consider both the probability of gene flow and its potential consequences. Asian cultivated rice (Oryza sativa L.) originated in Asia and is closely related to two wild species that are widespread and abundant on that continent: the perennial species $O$. rufipogon and the annual species $O$. nivara (Lu and Snow, 2005). Various types of weedy rice ( $O$. sativa), sometimes designated as $O$. sativa f. spontanea, also occur in and around rice fields in Asia and other rice-growing regions of the world. Weedy rice reduces yield and grain quality, and becomes a problem of increasing severity where direct seeding replaces transplanting as the method of crop establishment (Baki et al., 2000; references in Cao et al., 2007). Approximately $90 \%$ of rice fields in the Mekong Delta, in all habitats, are now established by direct seeding (L.M.C. and L.P.L, personal observations). Some weedy rices probably originate from rice cultivars that reverted to weedy forms, while others are derived from hybridization between cultivars and wild rice (e.g., Cao et al., 2006; Suh et al., 1997).

The probability of pollen-mediated gene flow can be quantified by studying the ability of the crop to hybridize and backcross with its wild and weedy relatives, proximity to wild and weedy populations, the longevity and dispersal of pollen, and the overlap of flowering times between transgenic and recipient plants in the field (Dale et al., 2002). Several studies have demonstrated that pollen from rice cultivars can fertilize $O$. rufipogon (Chen et al., 2004; Kuroda et al., 2005, Song et al., 2003; Wang et al., 2006) and weedy rice (Chen et al., 2004; Gealy et al., 2003; Messeguer et al., 2004) under field conditions, and that the resulting hybrids are fertile. Hybridization rates among these taxa are generally low, in the range of 0.01 to $3 \%$. However, crop-wild hybridization rates from an herbicide-resistant GM rice variety to $O$. rufipogon in experimental plots in China were as high as $18 \%$ when plants were immediately adjacent to the crop, $11 \%$ at $1 \mathrm{~m}$ from the crop, and $0.01 \%$ at $250 \mathrm{~m}$ from the crop (Wang et al., 2006). Because of the extensive area over which $O$. rufipogon and weedy rices co-occur with cultivated rice, and the large area over which transgenic rice cultivars may eventually be grown, transgenes will almost certainly disperse into populations of wild and weedy rice and could persist for many generations (Chen et al., 2004; Lu et al., 2003).

Due to the advanced state of development of transgenic rice cultivars, there is an urgent need for research on the extent and consequences of outcrossing to wild and weedy populations. Possible consequences depend on factors such as the fitness advantage or disadvantage conferred by the transgene on wild or weedy relatives and effects on other species in the ecosystem, should the recipient plant populations change in distribution, abundance, or toxicity (Letourneau et al., 2003). The large genetic variation within cultivated, wild, and weedy rices, the diversity of habitats in which rice is grown, and the diversity of transgenic traits under development necessitate case-by-case studies of the consequences of gene flow. The most direct method for evaluating the consequences of gene flow is to quantify the fitness effects of a transgene on hybrids between a transgenic cultivar and a wild or weedy relative under field conditions. For example, Snow et al. (2003) found that a Bacillus thuringiensis (Bt) gene conferring resistance to lepidopteran herbivores increased the fecundity of hybrids between a sunflower cultivar and wild sunflower. In contrast, Burke and Rieseberg (2003) found that an oxalate oxidase transgene for white mold resistance did not confer a fecundity advantage to crop-wild hybrids in sunflower.

Unfortunately, opportunities to study the fitness effects of transgenes directly are rare, in part because of strict regulations for conducting field experiments prior to deregulation. Countries in Asia have strict biosafety regulations governing the field testing of transgenic rice. While numerous field tests of transgenic rice have occurred in China and India, other countries have not yet approved field testing or have conducted only a handful of small-scale tests. Even in countries where field testing is permitted, it is likely to be difficult to obtain approval for field experiments involving hybrids between transgenic rice cultivars and wild or weedy rice because the use of such hybrids in field experiments could increase the risk of transgene escape into the wider environment. Consequently, there is a need for studies such as those we report in this paper that address gene flow and its potential consequences without using transgenic plants.

In this study, we surveyed flowering phenology and the presence of common insect herbivores and pathogens on cultivated, wild, and weedy rice populations in three habitats (fresh water, saline water, and acid sulfate soil) of the Mekong Delta of Vietnam, which is a major rice producer and exporter (Fig. 1, Tab. 1). Hereafter, we refer to $O$. rufipogon as wild rice (another wild rice, O. nivara, was not seen at our study sites). Wild rice occurs near cultivated rice throughout the Mekong Delta and is often the dominant vegetation along the banks of canals and irrigation ditches. Weedy rice also is common and grows intermixed with cultivated rice. Evidence for overlapping flowering times among our study species would indicate whether it is possible for crop-derived genes to spread to wild and weedy populations under current farming practices. Thus, the first objective of our study was to examine the potential for pollen-mediated gene flow from the crop to its wild and weedy relatives by examining flowering phenology in three common habitats where the crop is grown. 

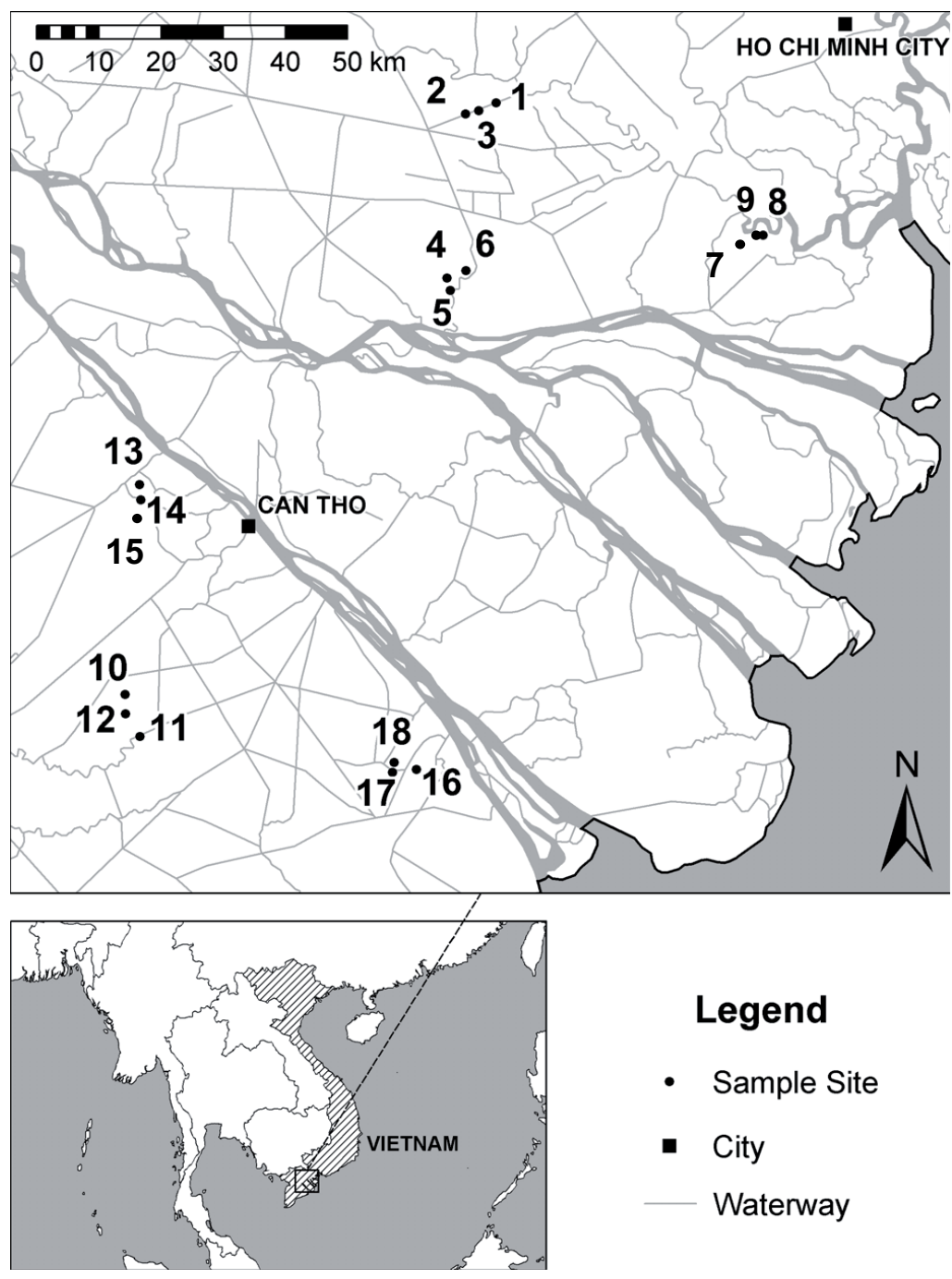

\section{Legend}

- Sample Site

- City

Waterway

Figure 1. Location of study sites in the Mekong Delta, Vietnam. The sites include three habitats: acid sulfate (1-3, 10-12), fresh water $(4-6,13-15)$, and saline $(7-9,16-18)$.

The second objective was to examine the distribution and relative abundance of common insect herbivores and pathogens in populations of wild, weedy, and cultivated rice, as a first step toward evaluating possible fitness effects of future transgenes that disperse into wild and weedy populations. While the pathogens and insects that attack the rice crop in Vietnam have been extensively studied (e.g., Cuong et al., 1997; Savary et al., 2000), little is known about the pathogens and insects that are found on wild and weedy rice in Vietnam or other rice-growing countries (Lu and Snow, 2005). Although many papers report on the survival of pathogens and insect herbivores of cultivated rice on $O$. rufipogon under greenhouse conditions, we found only two published papers describing field studies of the ecology of pathogens or insect herbivores on wild rice in Asia: one on rice gall midge (Orseola oryzae Wood-Mason) on wild rice in Thailand (Kadkao, 1991), and the second on rice tungro virus disease in the Philippines (Tiongco et al., 1993). Therefore, further studies of herbivores and pathogens of wild and weedy rice are needed assess the ecological and evolutionary effects of deploying transgenic rice that is resistant to these pests. Determining whether these pests are present in wild and weedy rice populations is a necessary component of risk assessment.

Transgenes that confer resistance to insects or pathogens could result in changes in the distribution or abundance of wild or weedy rice should they provide a fitness advantage. A few examples of transgenes for pest protection that have already been used in rice 
M.B. Cohen et al.

Table 1. Rice sampling sites in the Mekong Delta, Vietnam.

\begin{tabular}{|c|c|c|c|c|c|}
\hline Site no. & Habitat & Province & District & Town or village & Coordinates \\
\hline \multicolumn{6}{|c|}{ Northern sites } \\
\hline 1 & Acid sulfate & Long An & Thanh Hoa & Thanh Hoa & $\begin{array}{l}\text { N } 10^{\circ} 38^{\prime} 47.39^{\prime \prime} \\
\text { E } 106^{\circ} 08^{\prime} 55.59^{\prime \prime}\end{array}$ \\
\hline 2 & Acid sulfate & Long An & Thanh Hoa & Thuy Tay & $\begin{array}{l}\text { N } 10^{\circ} 37^{\prime} 50.62^{\prime \prime} \\
\text { E } 106^{\circ} 06^{\prime} 14.48^{\prime \prime}\end{array}$ \\
\hline 3 & Acid sulfate & Long An & Thanh Hoa & Thuy Tay & $\begin{array}{l}\text { N } 10^{\circ} 38^{\prime} 07.03^{\prime \prime} \\
\text { E } 106^{\circ} 07^{\prime} 24.79^{\prime \prime}\end{array}$ \\
\hline 4 & Fresh water & Tien Giang & Cai Lay & Phu An & $\begin{array}{l}\text { N } 10^{\circ} 23^{\prime} 31.43^{\prime \prime} \\
\text { E } 106^{\circ} 04^{\prime} 33.70^{\prime \prime}\end{array}$ \\
\hline 5 & Fresh water & Tien Giang & Cai Lay & Cam Son & $\begin{array}{l}\text { N } 10^{\circ} 22^{\prime} 27.30^{\prime \prime} \\
\text { E } 106^{\circ} 04^{\prime} 49.50^{\prime \prime}\end{array}$ \\
\hline 6 & Fresh water & Tien Giang & Cai Lay & Thanh Hoa & $\begin{array}{l}\text { N } 10^{\circ} 24^{\prime} 10.79^{\prime \prime} \\
\text { E } 106^{\circ} 06^{\prime} 13.69^{\prime \prime}\end{array}$ \\
\hline 7 & Saline & Long An & Chau Thanh & Thanh Phu Long & $\begin{array}{l}\text { N } 10^{\circ} 26^{\prime} 32.26 " \\
\text { E } 106^{\circ} 31 ' 28.74 "\end{array}$ \\
\hline 8 & Saline & Long An & Chau Thanh & Thuan My & $\begin{array}{l}\text { N } 10^{\circ} 27^{\prime} 07.33^{\prime \prime} \\
\text { E } 106^{\circ} 32^{\prime} 55.96^{\prime \prime}\end{array}$ \\
\hline 9 & Saline & Long An & Chau Thanh & Thuan My & $\begin{array}{l}\text { N } 10^{\circ} 27^{\prime} 09.29 " \\
\text { E } 106^{\circ} 32 ' 23.84 "\end{array}$ \\
\hline \multicolumn{6}{|c|}{ Southern sites } \\
\hline 10 & Acid sulfate & Can Tho & Phung Hiep & Hoa An & $\begin{array}{l}\text { N } 09^{\circ} 47^{\prime} 15.67^{\prime \prime} \\
\text { E } 105^{\circ} 36^{\prime} 07.44^{\prime \prime}\end{array}$ \\
\hline 11 & Acid sulfate & Can Tho & Phung Hiep & Phuong Binh & $\begin{array}{l}\mathrm{N} 09^{\circ} 43^{\prime} 34.70^{\prime \prime} \\
\mathrm{E} 105^{\circ} 37^{\prime} 25.51^{\prime \prime}\end{array}$ \\
\hline 12 & Acid sulfate & Can Tho & Phung Hiep & Hoa An & $\begin{array}{l}\text { N } 09^{\circ} 45^{\prime} 33.72^{\prime \prime} \\
\text { E } 105^{\circ} 36^{\prime} 09.23^{\prime \prime}\end{array}$ \\
\hline 13 & Fresh water & Can Tho & Omon & Thoi Thanh & $\begin{array}{l}\mathrm{N} 10^{\circ} 05^{\prime} 34.41^{\prime \prime} \\
\mathrm{E} 105^{\circ} 37^{\prime} 25.55^{\prime \prime}\end{array}$ \\
\hline 14 & Fresh water & Can Tho & Omon & Dinh Mon & $\begin{array}{l}\text { N } 10^{\circ} 04^{\prime} 14.04^{\prime \prime} \\
\text { E } 105^{\circ} 37^{\prime} 31.98^{\prime \prime}\end{array}$ \\
\hline 15 & Fresh water & Can Tho & Omon & Truong Lac & $\begin{array}{l}\text { N } 10^{\circ} 01^{\prime} 13.26^{\prime \prime} \\
\text { E } 105^{\circ} 36^{\prime} 56.92^{\prime \prime}\end{array}$ \\
\hline 16 & Saline & Soc Trang & Long Phu & Truong Khanh & $\begin{array}{l}\text { N } 09^{\circ} 40^{\prime} 38.84^{\prime \prime} \\
\text { E } 106^{\circ} 01^{\prime} 42.60^{\prime \prime}\end{array}$ \\
\hline 17 & Saline & Soc Trang & Long Phu & Truong Khanh & $\begin{array}{l}\text { N } 09^{\circ} 40^{\prime} 23.50^{\prime \prime} \\
\text { E } 105^{\circ} 59^{\prime} 36.48^{\prime \prime}\end{array}$ \\
\hline 18 & Saline & Soc Trang & Long Phu & Truong Khanh & $\begin{array}{l}\mathrm{N} 09^{\circ} 41^{\prime} 15.75^{\prime \prime} \\
\text { E } 105^{\circ} 59^{\prime} 47.13^{\prime \prime}\end{array}$ \\
\hline
\end{tabular}

transformation and could become available in Vietnam and elsewhere include $B t$ and cowpea trypsin inhibitor genes for resistance to lepidopteran larvae (High et al., 2004; Huang et al., 2005), lectin genes for resistance to sucking insects (Nagadhara et al., 2003; Saha et al., 2006), chitinase or allene oxide synthase genes for resistance to fungal diseases (Datta et al., 2001; Mei et al., 2006), and trangenes for resistance to bacterial blight (Zai et al., 2004). Other transgenic traits that could be released separately or in combination with various types of pest resistance include resistance to commonly used herbicides, greater tolerance of abiotic stresses, and enhanced production of pro-vitamin A (e.g., Lu and Snow, 2005).

\section{RESULTS}

\section{Phenology}

\section{Cultivated rice}

All the rice fields we sampled were planted to modern semidwarf varieties, with the exception of a few fields 
in the saline habitat that were planted to traditional varieties. Modern varieties do not require specific photoperiods to induce flowering, so it is possible for farmers to grow more than one rice crop per year. The temporal pattern of crop establishment varied from year to year within sites (Fig. 2), and this may be due in part to variation in the start and duration of the annual flooding of the delta (fields cannot be planted until the flood levels subside). In non-saline habitats in the Mekong Delta, cultivated rice can be planted at most times of the year, and most farmers grow three rice crops per year on a given piece of land. In saline areas, only one or two crops can be grown per year, due to excessive water salinity during the dry season.

Over the course of the study, one or more of the 12 non-saline crop fields flowered in each month of the year except November and December (Fig. 2). At the six saline sites, the crop was most likely to flower in November-January and June-August, depending on the location and year, but some flowering occurred in every month except April and May. Fields in the acid sulfate habitat of the southern region were occasionally found to have ratoon rice, i.e., regrowth from rice stubble after harvest (Fig. 2). Ratoon rice can arise if fields are not plowed or flooded shortly after harvest. Ratoon plants develop to flowering and maturity if left undisturbed and thus may lead to increased temporal overlap in flowering between cultivated rice and its wild relatives.

\section{Weedy rice}

Flowering periods of weedy rice frequently overlapped with flowering of cultivated rice in the same field (Fig. 2). Because weedy rice is an annual, each episode of flowering is likely to represent a separate cohort of plants, which we refer to as a population. (Thus, there were more "populations" than sites.) At the northern sites (1-9), all of the 29 populations that we observed flowered during the same month as the surrounding crop plants (Fig. 2). At the southern sites (10-18), 63\% of 43 weedy populations overlapped with the crop. In both regions, a few weedy populations also flowered during the same month as the nearby population of $O$. rufipogon $(10 \%$ in the northern region and $26 \%$ in the southern region).

\section{Oryza rufipogon}

The peak of $O$. rufipogon flowering typically occurred between November and January, when fresh water crop fields were often fallow (Fig. 2). Flowering times varied across years and locations, and we observed considerable variation in flowering times within sites, with some plants flowering as late as April (data not shown). The duration of flowering in a population often spanned several months, unlike the single month duration for cultivated and weedy rice populations. There were several cases in which the flowering times of cultivated and weedy rice overlapped with the peak flowering times of adjacent $O$. rufipogon populations. These included all six of the saline water sites and the three southern acid sulfate sites. In 2002, peak flowering at two of the southern acid sulfate sites occurred in June.

The flowering times of $O$. rufipogon populations are probably influenced by the annual floods, and are strongly affected by the activity of farmers and farm animals. Farmers at several sites cut $O$. rufipogon to feed to buffalo or to facilitate boat movement along canals, and at some sites buffalo and domesticated ducks grazed directly on the wild rice. At sites 13, 14 and 15 in the 2001-2002 season, and at sites 1, 2, and 3 in the 20022003 season, cutting and grazing were so extensive that the O. rufipogon populations did not flower (Fig. 2).

\section{Insects and pathogens}

Numerous species of pathogens and insect herbivores, or symptoms of their pathology or feeding, were observed on wild, weedy, and cultivated rice. All of the most frequently observed insects and pathogens (Tab. 2) are common pests of cultivated rice (IRRI, 1983). We report data from the nine northern sites only. All of the insects and pathogens in Table 2 were found on cultivated, wild, and weedy rice (Fig. 3). Damage by leaffolders and locusts was the most frequently observed insect feeding damage on all three rice types. The percentage of leaves with leaffolder damage on specific sampling dates ranged as high as 29,38 , and $26 \%$ for wild, weedy, and cultivated rice, respectively (data not shown). Locust damage ranged as high as 100,12 , and $18 \%$ for wild, weedy, and cultivated rice, respectively (data not shown).

To further examine the relative abundance of insects and pathogens on $O$. rufipogon, we analyzed data from a series of 16 dates between January 2001 and November 2002 , for which data were available from all nine of the northern study sites. We note that because the three sites for each habitat were clustered geographically, possible effects of habitat on species abundances could be confounded with effects of spatial proximity. We used different multivariate tests to identify specific associations of taxa with habitats. First, the ordination of data obtained with a non-metric multidimensional scaling analysis showed a fairly distinct pattern of pest species among the three habitats (Fig. 4), with the saline habitat showing a more unique species composition compared to the others. Stress is reduced from 42.61 to 8.83 by representing the space in three axes. The stress reduction between 


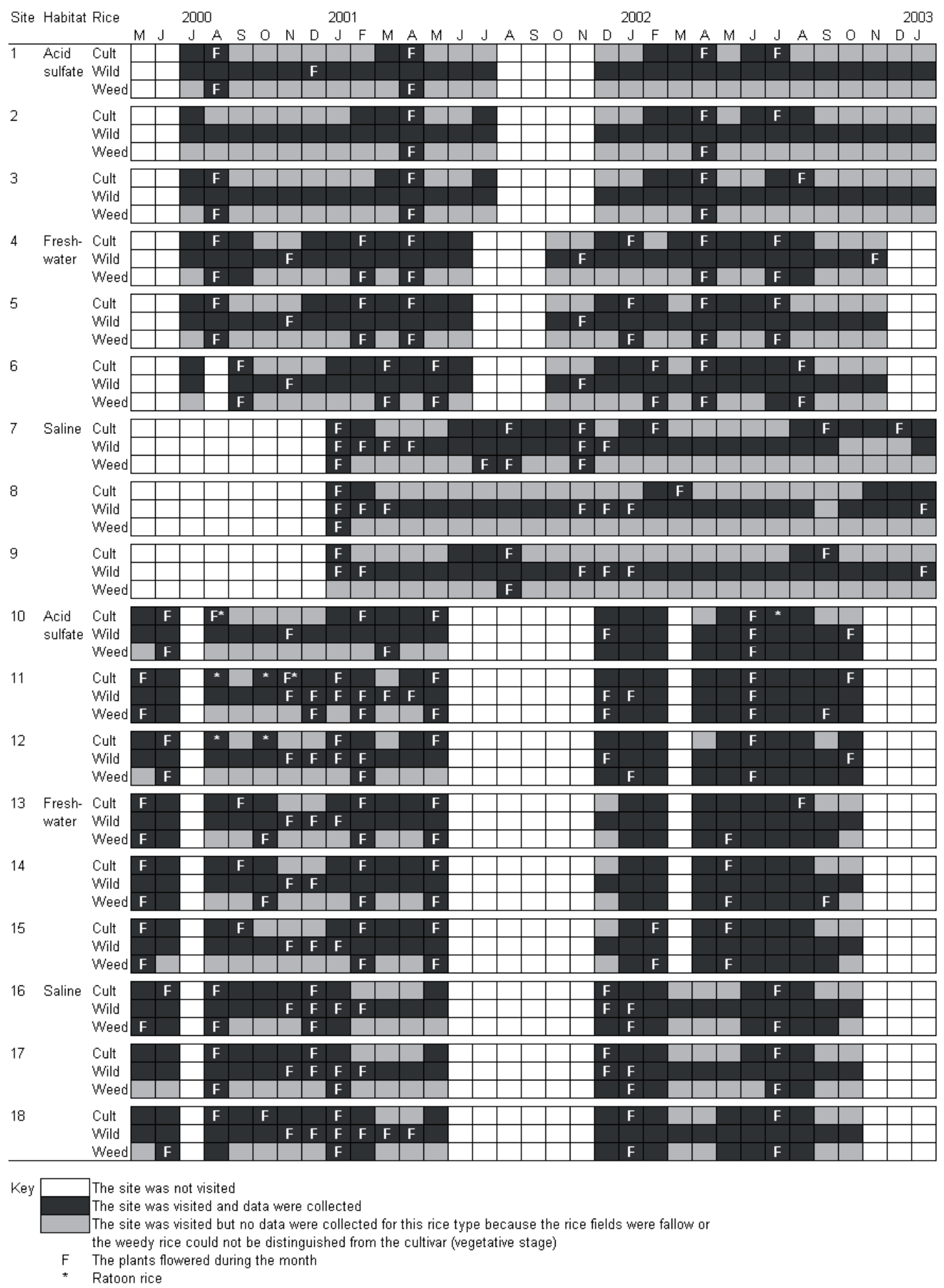

Figure 2. Flowering phenology of wild, weedy, and cultivated rice in three habitats of the northern (sites 1-9) and southern (sites 10-18) Mekong Delta, Vietnam. Ratoon rice refers to cutting, which prevents or delays flowering. 
Flowering phenology and pests of wild and weedy rice

Table 2. Insects and pathogens sampled for abundance on wild, weedy, and cultivated rice in the northern sites (sites 1-9).

\begin{tabular}{|c|c|c|c|}
\hline Taxon & Latin name & Common name & $\begin{array}{l}\text { Method of quantification } \\
\text { of abundance }\end{array}$ \\
\hline \multicolumn{4}{|l|}{ Insects } \\
\hline \multirow[t]{2}{*}{ Orthoptera } & Acrididae & Locust & No. of leaves with damage symptoms \\
\hline & Gryllidae & Cricket & No. of leaves with damage symptoms \\
\hline \multirow[t]{4}{*}{ Hemiptera } & Nephotettix spp. & Green leafhopper & No. of insects per tiller \\
\hline & Nilaparvata lugens (Stål) & Brown planthopper & No. of insects per tiller \\
\hline & Sogatella furcifera (Horwath) & White-backed planthopper & No. of insects per tiller \\
\hline & Leptocorisa spp. & Rice bug & No. of insects per tiller \\
\hline \multirow[t]{2}{*}{ Lepidoptera } & $\begin{array}{l}\text { Scirpophaga incertulas } \\
\text { (Walker), Chilo spp. }\end{array}$ & Stem borer ${ }^{2}$ & No. of tillers with damage symptoms \\
\hline & $\begin{array}{l}\text { Cnaphalocrocis medinalis } \\
\text { (Guenée), Marasmia spp. }\end{array}$ & Leaffolder & No. of leaves with damage symptoms \\
\hline \multicolumn{4}{|l|}{ Pathogens } \\
\hline \multirow[t]{2}{*}{ Fungi } & Rhizoctonia solani Kühn & Sheath blight & No. of tillers with damage symptoms \\
\hline & Magnaporthe grisea (Herbert) Barr & Blast & No. of leaves with damage symptoms \\
\hline \multirow[t]{2}{*}{ Bacteria } & Xanthomonas oryzae pv. oryzae & Bacterial leaf blight & No. of leaves with damage symptoms \\
\hline & $\begin{array}{l}\text { Helminthosporium oryzae Breda } \\
\text { de Hann }\end{array}$ & Brown spot & No. of leaves with damage symptoms \\
\hline
\end{tabular}

${ }^{1}$ At each site, we sampled 25 tillers at each sample point, using 5 sample points per site for wild rice, and 8 sample points per site for both weedy and cultivated rice. For those insects and pathogens that we recorded on $O$. rufipogon and weedy rice on the basis of characteristic damage symptoms, further study is needed to confirm that the causative agents were in fact the same species as those known to produce comparable symptoms on cultivated rice.

${ }^{2}$ Damage from stem borers is known as deadheart for stems and whitehead for seed heads.

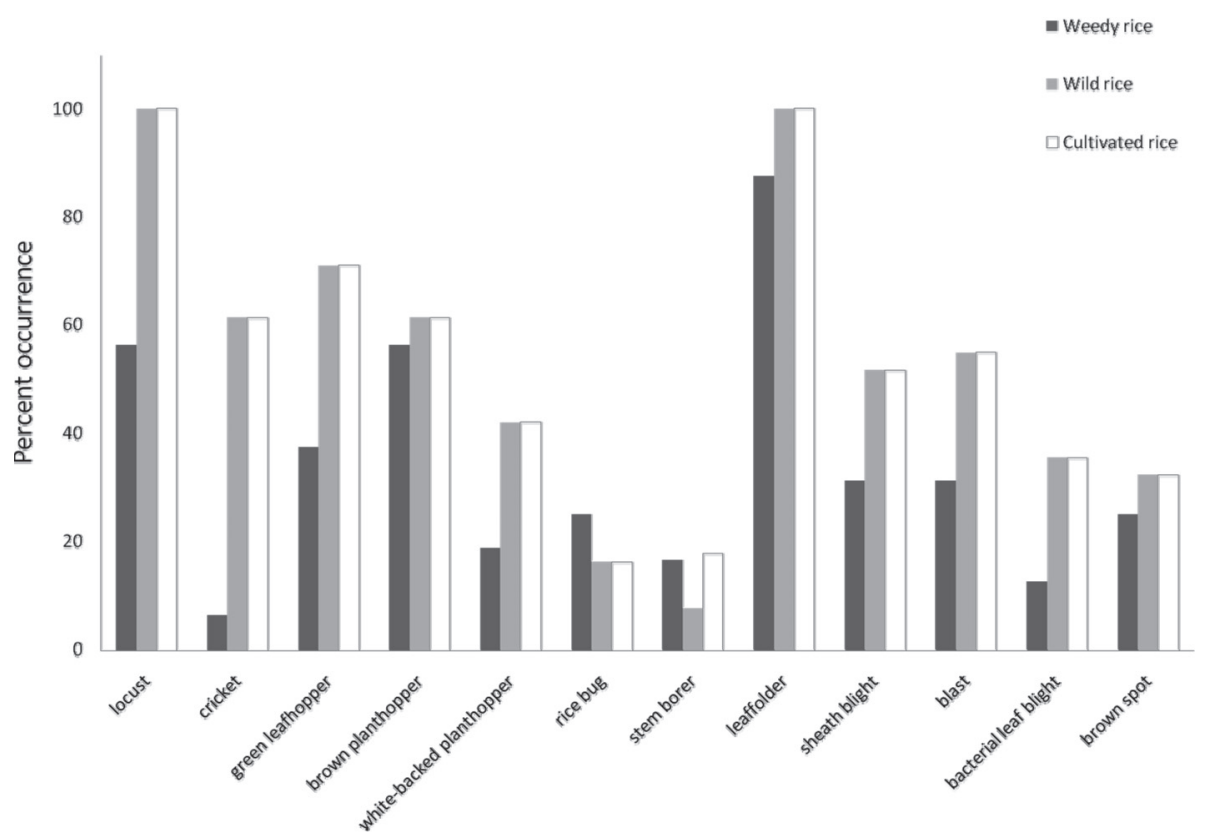

Figure 3. Percent occurrence of tillers with damage symptoms and presence of hemipterans, based on pooled data from all sample points and dates in the northern region of the Mekong Delta, Vietnam. Insect and pathogen species are listed in Table 2. Numbers of sample points: weedy rice $n=98$, wild rice $n=224$, cultivated rice $n=848$. 


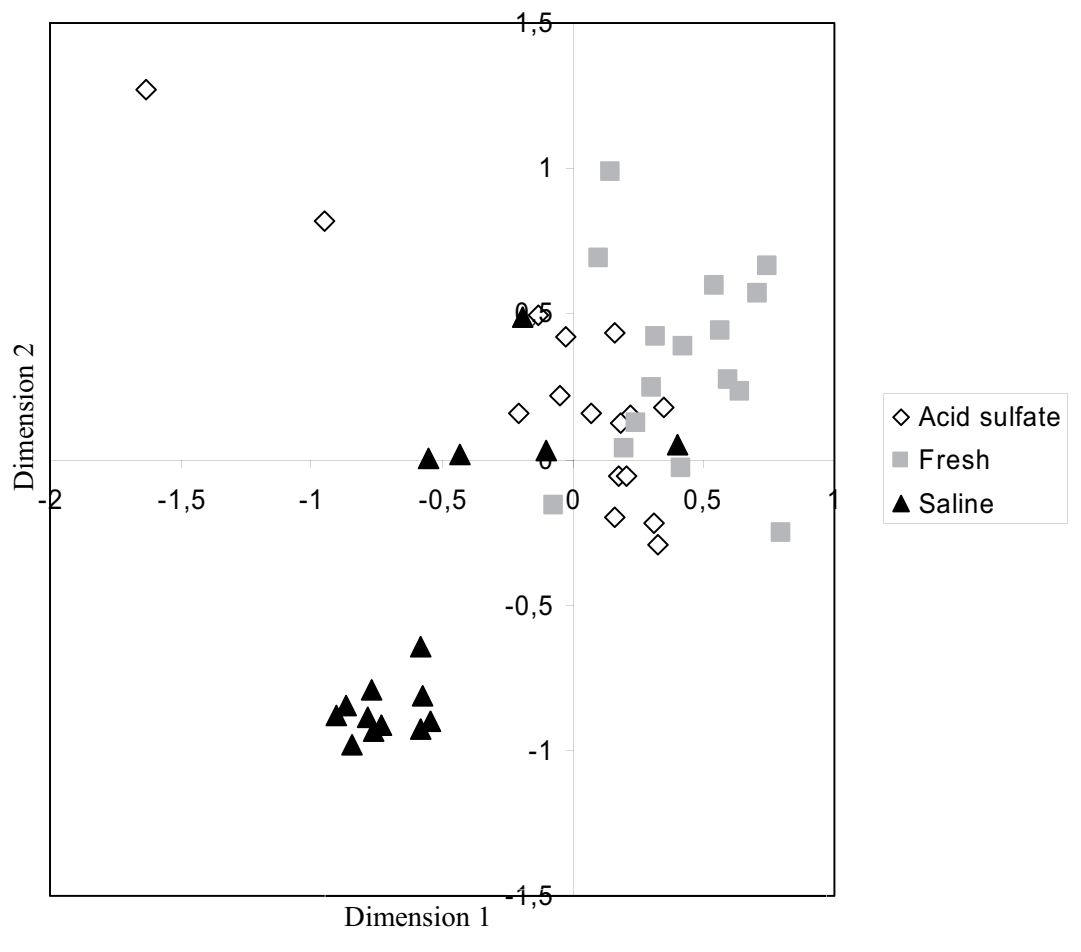

Figure 4. Non-metric multidimensional scaling analysis for insect and pathogen data for wild rice (O. rufipogon) from the northern region of the Mekong Delta, Vietnam. First and second axes are represented, accounting for $56.7 \%$ and $9.5 \%$ of the total variation, respectively.

the second and third axis has a value of 15.40 , resulting in a $P$ value of 0.066 , indicating an efficient fit of data points in a three-dimensional space. This indicates that the ordination of data points is reached quite efficiently.

The coupled use of multiple response permutation procedure and indicator species analysis showed that most of the insect herbivores were significantly associated with one of the three habitats, as was one of the four diseases (blast, which was associated with fresh water sites). Leaffolders and green leafhoppers were more strongly associated with fresh water sites than the acid sulfate or saline sites. Indicator species analysis combines information on a species' relative abundance with its relative frequency of occurrence in the various groups of sites, and these two types of information were combined in the indicator values shown in Table 3 . The overall association between taxa and habitat was also highly significant $(P<0.0001)$.

\section{DISCUSSION}

It is well known that $O$. rufipogon, weedy rice, and cultivated $O$. sativa can be readily crossed under controlled conditions and that hybridization can occur under field conditions (Chen et al., 2004; Song et al., 2003). Our observations on flowering phenology provide further evidence that transgenes will almost certainly enter populations of weedy and wild rice in the Mekong Delta. Weedy rice frequently flowered at the same time as the crop and was intermixed with crop plants. Wild rice has a higher outcrossing rate than weedy rice (e.g., Song et al., 2003), but we found that seasonal opportunities for hybridization were less common in wild rice, which often flowered in November and December (also reported by Kuroda et al., 2005, for populations in Laos). During the two-year period of this study, the peak flowering time of $O$. rufipogon coincided with flowering of a neighboring rice field at nine of the 18 sites. These nine sites included all six of the saline sites, and the three acid sulfate sites in the southern region. It should be noted that the area of saline rice cultivation in the Mekong Delta is much smaller than that of the acid sulfate and fresh water areas, and is declining. Thus, the proportion of total outcrossing events in the Mekong Delta that occurs in saline areas is likely to be relatively small. The lack of flowering overlap between cultivated and wild rice in fresh water areas could be a general pattern or it could be a result of small sample sizes (six wild populations studied during two years) and harvesting by farmers. In any 
case, we often observed a few individuals of $O$. rufipogon flowering earlier or later than the peak months indicated in Figure 2, such that crop-to-wild gene flow could occur sporadically in fresh water areas.

Given the strong likelihood of transgenes entering weedy and wild rice populations in the Mekong Delta, environmental risk assessment requires information about how specific transgenes might affect the fecundity and abundance of recipient populations. To address the consequences of transgene outcrossing to O. rufipogon or weedy rice, information on the ecology and biotic and abiotic stress resistance of these plants is needed. Although we did not test for such consequences, our study provides new information on the insect pests and diseases that occur on $O$. rufipogon and weedy rice.

Common pathogens and insect herbivores on cultivated rice were also found on wild and weedy rice, indicating that further research on the consequences of releasing pest-protection transgenes is warranted. Our results are not surprising given that $O$. rufipogon, weedy rice, and cultivated rice are closely related and share the same or adjacent habitats, and that $O$. rufipogon can serve as a host to numerous rice pathogens and insect pests under greenhouse conditions (e.g. Eizenga et al., 2002; Romena and Heinrichs, 1989). In addition, O. rufipogon accessions with resistance to brown planthopper, green leafhopper, white-backed planthopper, bacterial blight, and rice tungro virus disease have been identified (Bellon et al., 1998; Romena and Heinrichs, 1989), and it is possible that this resistance evolved in response to herbivory and disease pressure. Nonetheless, our results show that some $O$. rufipogon and weedy rice populations serve as hosts for these pests in the field and therefore might gain increased fitness from the introgression of novel, transgenic resistance transgenes.

Genes conferring high levels of natural resistance to some common rice pathogens and insect herbivores, including stem borers, leaffolders, locusts, and sheath blight, have not been reported in cultivated or weedy rice or O. rufipogon (e.g., Bonman et al., 1992; Heinrichs, 1994). Because major resistance to these pests is apparently absent from $O$. sativa and $O$. rufipogon, the consequences of outcrossing of transgenes conferring resistance to these pests should receive particularly careful evaluation in future studies. Locusts and leaffolders caused the most frequent insect feeding damage observed on $O$. rufipogon and weedy rice. Cultivated rice has been shown to recover from high levels of early season defoliation (Matteson, 2000), but responses of wild and weedy rice to natural levels of leaf damage are not known. Feeding by stem borers at the reproductive stage prevents grain production in the affected tiller and may therefore have a larger effect on fitness than partial defoliation, but we observed only low levels of stem borer damage in all habitats and rice types in our study. This is consistent with general patterns of stem borer infestation in tropical rice (High et al., 2004; Savary et al., 2000).

Direct comparisons of insect and pest damage among rice species are not warranted because it was not possible to sample all three rice taxa on all of the sampling dates, so the data are not balanced with regard to plant life stages or seasonal variation in the occurrence of insects and pathogens. Thus, although weedy rice appears to have less damage than wild or cultivated rice (Fig. 3), this could be due to a lack of data from young plants.

Statistical analysis of the $O$. rufipogon data revealed significant variation in the abundance of some pest species (i.e., locust, cricket, green leafhopper, whitebacked planthopper, stem borer, leaffolder, blast) among habitats (Tab. 3, Fig. 4). The saline habitat presents the most distinct pattern of species distribution, with relatively common occurrences of crickets, locusts, and white-backed planthoppers and low frequencies of several other taxa. This is not a surprising outcome, as many organisms are sensitive to salinity. Although our analysis of habitat associations was restricted to grouped sites in the northern region, our results indicate the importance of broad geographic sampling to account for spatial variation in pest species. It must be noted that the use of multivariate tests combining actual data counts and detection of symptoms has only a comparative value. Therefore our results should not be used to draw conclusions about the abundance of insect or pathogen populations in other areas of rice cultivation.

In conclusion, this study demonstrates that hybridization between cultivated rice and its wild and weedy relatives is very likely in Vietnam, making it necessary to understand the consequences of transgenic traits that could introgress into recipient populations. We also found that wild and weedy rice are hosts of many of the common pest species of cultivated rice. Therefore, further studies are needed to determine whether release from natural levels of pest pressure due to transgene introgression is likely to enhance the fitness of wild and weedy rice, and whether this could pose problems for farmers or the environment. Other transgenic traits, such as those that confer herbicide resistance and drought tolerance, also have the potential to be beneficial for wild and weedy taxa, whereas nutritional transgenic traits might be neutral or deleterious (this has yet to be examined). Ultimately, decisions about which transgenic rice lines should be released into the environment will hinge on broader considerations of their likely benefits and risks. Ecological field surveys such as ours provide a crucial starting point for making informed decisions about deregulation. 
Table 3. Indicator values (based on relative abundance and percentage of samples where a species was present) and significance of the association for data on Oryza rufipogon from three habitats (fresh water, acid sulfate, or saline) in the northern Mekong Delta, Vietnam, from January 2001 to November 2002. Bold numbers indicate a significant association with a specific habitat. $P *=$ proportion of randomized trials with indicator values equal to or exceeding the observed indicator value. Sampling dates used in this table are a subset of those used in Figure 3.

\begin{tabular}{|c|c|c|c|c|c|c|}
\hline Taxon & Fresh water & Acid sulfate & Saline & $\begin{array}{l}\text { Expected indicator } \\
\text { values }( \pm \mathrm{SD})\end{array}$ & $\begin{array}{l}\text { Observed indicator } \\
\text { values }\end{array}$ & $P^{*}$ \\
\hline \multicolumn{7}{|l|}{ Orthoptera } \\
\hline Locust & 32 & 24 & 43 & $37.6 \pm 2.99$ & 42.7 & 0.054 \\
\hline Cricket & 0 & 0 & 79 & $18.4 \pm 5.57$ & 78.5 & 0.000 \\
\hline \multicolumn{7}{|l|}{ Hemiptera } \\
\hline Green leafhopper & 42 & 0 & 1 & $21.1 \pm 7.28$ & 42.1 & 0.015 \\
\hline Brown planthopper & 25 & 1 & 8 & $21.7 \pm 7.35$ & 24.7 & 0.290 \\
\hline W-B planthopper & 0 & 1 & 28 & $11.1 \pm 5.06$ & 27.8 & 0.024 \\
\hline Rice bug & 6 & 0 & 0 & $6.2 \pm 0.2$ & 6.3 & 0.999 \\
\hline \multicolumn{7}{|l|}{ Lepidoptera } \\
\hline Stem borer & 4 & 46 & 1 & $20.5 \pm 6.31$ & 45.9 & 0.003 \\
\hline Leaffolder & 59 & 12 & 22 & $38.8 \pm 5.06$ & 58.9 & 0.001 \\
\hline \multicolumn{7}{|l|}{ Fungi } \\
\hline Sheath blight & 20 & 2 & 7 & $18.9 \pm 7.0$ & 19.7 & 0.403 \\
\hline Blast & 40 & 3 & 0 & $23.0 \pm 7.92$ & 39.7 & 0.040 \\
\hline \multicolumn{7}{|l|}{ Bacteria } \\
\hline Bacterial leaf blight & 11 & 0 & 5 & $21.9 \pm 7.71$ & 10.7 & 0.915 \\
\hline Brown spot & 8 & 0 & 11 & $15.1 \pm 6.90$ & 11.0 & 0.669 \\
\hline
\end{tabular}

\section{MATERIALS AND METHODS}

\section{Study sites}

Eighteen study sites were selected based on location, habitat type, and co-occurrence of wild and cultivated rice (Fig. 1, Tab. 1). Each site encompassed an area of approximately 10 ha that included a cultivated rice field and at least one population of wild rice growing along the banks of a canal within $3 \mathrm{~m}$ of the edge of the crop. Most of the rice fields also had populations of weedy rice, though not all.

We established nine study sites in a northern region and nine in a southern region. Within each region, we selected three sites in each of three current or historical habitat types that are common in the Mekong Delta: fresh water, saline water, and acid sulfate soil. The sites within a habitat were separated by at least $5 \mathrm{~km}$. Within each region, the sites were clustered by habitat rather than randomly interspersed due to the geographic extent of the habitats. The sites ranged in elevation from 5 to $20 \mathrm{~m}$ above sea level.

In the saline habitats, salinity levels are variable and may be lower than in the past. Seasonally, the salinity of the water increases during the dry season as freshwater entering the Mekong Delta declines and sea water intrusion increases. On a daily basis, salinity declines as the tide recedes and increases as the tide rises. Over the past 30 years, the salinity of water in the canals in much of the Mekong Delta has declined as a result of the construction of levees that impede the intrusion of sea water. Consequently, while all of the sites that we categorize as saline historically had saline irrigation water, at the time of our study the salinity of the water had probably declined by varying degrees.

Acid sulfate soils occur in about $40 \%$ the Mekong Delta (e.g., Minh et al., 1997). The soil acidity results in greater solubility of aluminum, and aluminum toxicity impedes rice growth. Excavation of new canals and other disturbances result in the exposure of new soil that is higher in acid sulfate content, while the acidity within established fields may decline over time due to repeated cycles of tilling, flooding, and leaching. Vast areas of the Mekong Delta have been reclaimed for rice cultivation by this process. In some cases, the acidity and aluminum toxicity of surface soils at our study sites may be similar to those designated as fresh water sites, despite having an underlying soil horizon of reduced sulfur compounds in 
pyritic mud. Thus, there was probably a range in acidity among the sites that we designated as acid sulfate.

\section{Sampling methodology}

Wild, weedy, and cultivated rice plants were sampled on a monthly basis for 22 to 27 months at the 18 study sites, beginning in May 2000 and ending in October 2002. There were several gaps in the sampling over this time period, mainly due to logistical difficulties such as lack of access because of flooding. Plant growth stage (vegetative, flowering, seed ripening) was recorded at each sample site (see below) and date. Cultivated rice within a field flowered uniformly due to high varietal purity. The flowering time of weedy rice and wild rice populations at each study site was more variable. We recorded the date(s) of peak flowering, based on qualitative observations. If flowering occurred during the interval between two consecutive visits, the flowering time was interpolated to the month during which it was most likely to have occurred. At the nine northern sites, the abundance of eight insect taxa and four diseases were quantified on each sample date (Tab. 2). For four species of Hemiptera, which are common pests of cultivated rice, we counted the numbers of insects found on the sampled shoots. The abundance of other insects and the four pathogens was quantified by recording the presence or absence of characteristic damage symptoms (IRRI, 1983) on each leaf sampled (Tab. 2). A leaf was considered to be damaged if the symptoms were large enough for the causal agent of damage to be identified.

Methods for sampling shoots of wild, cultivated, and weedy rice are described below.

\section{O. rufipogon sampling}

At each site, sampling was conducted at five points spaced evenly along a $100-\mathrm{m}$ transect on one or both sides of a canal. At each sample point 25 tillers were examined within an area of $2 \mathrm{~m}^{2}$, for a total of 125 tillers per site on the date of sampling. $O$. rufipogon is capable of extensive vegetative reproduction, and a single individual may consist of dozens of tillers interspersed with tillers of other individuals. Thus, the 25 tillers sampled could have been part of one or more individual plants.

\section{Cultivated rice sampling}

Plants were sampled at eight widely spaced points in a farmer's field adjacent to the $O$. rufipogon sampling transect. At some sites, sampling points for cultivated rice were in two adjacent rice fields that were planted at approximately the same time. At each sample point, 25 tillers were examined within a $1-\mathrm{m}^{2}$ area, for a total of 200 tillers per site.

\section{Weedy rice sampling}

Weedy rice was sampled in farmers' fields, where it was interspersed with the rice crop. Weedy rice is difficult to distinguish from cultivated rice when the plants are at the vegetative stage. Thus, weedy rice was sampled only during the reproductive stage, when it could be identified on the basis of panicle height and appearance. The density and distribution of weedy rice within cultivated rice fields are variable. Weedy rice was sampled at eight points where the plants were present at sufficient density to allow 25 tillers to be examined within an area of approximately $1 \mathrm{~m}^{2}$ (200 tillers per site). In fields in which weedy rice was not abundant, no sampling was conducted.

\section{Data analysis}

For insects and pathogens at the nine northern sites, we calculated the percent occurrence at all sample sites and sample dates (Fig. 3). For wild rice, which was surveyed most consistently during this period, we also compared the occurrence of pest species in the three habitats. This analysis is based on 16 sampling dates from January 2001 to November 2002.

Occurrence of pest species was compared first with an ordination method, non-metric multidimensional scaling (NMS, Kruskal, 1964), and then with a multiple response permutation procedure (MRPP, Zimmerman et al., 1985). Possible associations between taxa and habitats were defined using indicator species analysis (ISA, Dufrene and Legendre, 1997). Ordination techniques are widely used for summarizing species responses to environmental factors. An "indirect gradient analysis" is performed when only species composition is measured and relationships with environmental variables are inferred on the basis of patterns in species distribution. NMS is a popular ordination method for indirect gradient analysis, which is well suited to data that are non-normal, or are on arbitrary, discontinuous scales. The goal of NMS is representing in the space data points such that pairwise distances between two of these have the rank order in the same order of magnitude of pairwise dissimilarities between raw data. In order to optimize this spatial representation, NMS algorithms start calculating an average pair distance. The difference between this estimate and an actual distance between points is called stress. Data are then shuffled in an iterative process in order to minimize discrepancies and reduce stress as much as possible until an adequate fit 
is obtained. A successful ordination of data points in the space with NMS is measured with a reduction of stress, expressed with a $P$ value.

The coupled use of MRPP and ISA furnishes robust quantitative estimates of biodiversity and may enable discovery of indicator species for the specific system. The tests were performed by summing, for each sampling date and habitat, data of insect counts (for white-backed planthopper, brown planthopper, green leafhopper, rice bug) or, for species that were recorded based on their symptoms (including pathogens), the mean percentages of damaged leaves or tillers.

\section{ACKNOWLEDGEMENTS}

We thank Bao-Rong Lu, Michael Reagon, and the Plant Population Ecology Group at Ohio State University for helpful comments on the manuscript; Nguyen Viet Minh, Nguyen Huu Quang, Nguyen Van Duong, Do Van Van, Hoang Duc Cat, Tran thi Mong Quyen, Luong thi Phuong, and Phan thi Ben for technical assistance in the field; and Charlene Nielsen for preparation of Figure 1. This work was funded by USAID Biodiversity and Biotechnology Interface grants to the International Rice Research Institute and A. Snow.

Received November 4, 2007; accepted April 7, 2008.

\section{REFERENCES}

AgBios (2007) GM crop database. http:// www.agbios.com/dbase.php (accessed October 11, 2007)

Baki BB, Chin DV, Mortimer AM, eds (2000) Wild and Weedy Rice in Rice Ecosystems in Asia - a Review. Los Baños (Philippines): International Rice Research Institute

Bellon MR, Brar DS, Lu BR, Phan JL (1998) Rice genetic resources. In Sustainability of Rice in the Global Food System, International Rice Research Insitute, Manila, Philippines, pp 251-283

Bonman JM, Khush GS, Nelson RJ (1992) Breeding rice for resistance to pests. Ann. Rev. Phytopathol. 30: 507-528

Burke JM, Rieseberg LH (2003) Fitness effects of transgenic disease resistance in sunflowers. Science 300: 1250

Cao QJ, Lu BR, Xia H, Rong J, Sala F, Spada A, Grassi F (2006) Genetic diversity and origin of weedy rice (Oryza sativa f. spontanea) populations found in North-eastern China revealed by simple sequence repeat (SSR) markers. Ann. Bot. 98: $1241-1252$

Cao QJ, Li B, Song ZP, Cai XX, Lu BR (2007) Impact of weedy rice populations on the growth and yield of directseeded and transplanted rice. Weed Biol. Manage. 7: 97-104
Chen LJ, Lee DS, Song ZP, Suh HS, Lu BR (2004) Gene flow from cultivated rice (Oryza sativa) to its weedy and wild relatives. Ann. Botany 93: 67-73

Cuong NL, Ben PT, Phuong LT, Chau LM, Cohen MB (1997) Effect of host plant resistance and insecticide on brown planthopper, Nilaparvata lugens (Stål) and predator population development in the Mekong Delta, Vietnam. Crop Protection 16: 707-715

Dale PJ, Clarke B, Fontes EMG (2002) Potential for the environmental impact of transgenic crops. Nat. Biotech. 20: 567574

Datta K, Tu JM, Oliva N, Ona I, Velazhahan R, Mew TW, Muthukrishnan S, Datta SK (2001) Enhanced resistance to sheath blight by constitutive expression of infection-related rice chitinase in transgenic elite indica rice cultivars. Plant Sci. 160: 405-414

Dufrene M, Legendre P (1997) Species assemblages and indicator species: the need for a flexible asymmetrical approach. Ecol. Monogr. 67: 345-366

Eizenga GC, Lee FN, Rutger JN (2002) Screening Oryza species plants for rice sheath blight resistance. Plant Dis. 86: 808-812

Ellstrand NC (2003) Dangerous Liaisons? When Cultivated Plants Mate with Their Wild Relatives. Johns Hopkins University Press, Baltimore

Gealy DR, Mitten DH, Rutger JN (2003) Gene flow between red rice (Oryza sativa) and herbicide-resistant rice $(O$. sativa): implications for weed management. Weed Tech. 17: 627-645

Giri CC, Laxmi GV (2000) Production of transgenic rice with agronomically useful genes: an assessment. Biotechnol. Adv. 18: $653-683$

Heinrichs EA (1994) Host plant resistance. In Biology and Management of Rice Insects, Heinrichs EA, ed, Wiley Eastern Limited and New Age International Limited, New Delhi, India, pp 517-547

High SM, Cohen MB, Shu Q, Altosaar I (2004) Achieving successful deployment of Bt rice. Trends Plant Sci. 9: 286292

Huang J, Hu R, Rozelle S, Pray C (2005) Insect-resistant GM rice in farmers' fields: assessing productivity and health effects in China. Science 308: 688-690

IRRI (1983) Field problems of tropical rice (revised edition). Los Baños (Philippines): International Rice Research Institute

James C (2006) Global status of commercialized biotech/GM crops: 2006. ISAAA Brief No. 35 (International Service for the Acquisition of Agri-biotech Applications): Ithaca, NY

Kadkao S (1991) Seasonal occurrence of the rice gall midge, Orseolia oryzae (Wood-Mason), in a wild rice field in Thailand and parasitism by its parasitoids, Platygaster oryzae (Cameron) and P. foersteri (Gahan) (Hymenoptera, Platygasteridae). Japn. J. Entomol. 59: 449-465

Khush GS (2001) Green revolution: the way forward. Nat. Rev. Genetics 2: 815-822

Kruskal J (1964) Multidimensional scaling by optimising goodness of t to a non-metrical hypothesis. Psychometrika 20: $1-27$ 
Kuroda Y, Sato Y-I, Bounphanousay C, Kono Y, Tanaka K (2005) Gene flow from cultivated rice (Oryza sativa L.) to wild Oryza species (O. rufipogon Griff. and O. nivara Sharma and Shastry) on the Vientiane plain of Laos. Euphytica 142: 75-83

Letourneau DK, Robinson GS, Hagen JA (2003) Bt crops: predicting effects of escaped transgenes on the fitness of wild plants and their herbivores. Environ. Biosafety. Res. 2: 219246

Lu BR, Snow AA (2005) Gene flow from genetically modified rice and its environmental consequences. BioScience 55: 669678

Lu BR, Song ZP, Chen JK (2003) Can transgenic rice cause ecological risks through transgene escape? Prog. Natural Science 13: 17-24

Matteson PC (2000) Insect pest management in tropical Asian irrigated rice. Annu. Rev. Entomol. 49: 549-574

Mei CS, Qi M, Sheng GY, Yang YN (2006) Inducible overexpression of a rice allene oxide synthase gene increases the endogenous jasmonic acid level, PR expression, and host resistance to fungal infection. Molec. Plant Microbe Interactions 19: $1127-1137$

Messeguer J, Marfa V, Catala MM, Guiderdoni E, Mele E (2004) A field study of pollen-mediated gene flow from Mediterranean GM rice to conventional rice and red rice weed. Molec. Breed. 13: 103-112

Minh LQ, Tuong TP, van Mensvoort MEF, Bouma J (1997) Contamination of surface water as affected by land use in acid sulfate soils in the Mekong River Delta, Vietnam. Agric. Ecosyst. Environ. 61: 19-27

Nagadhara D, Ramesh S, Pasalu IC, Rao YK, Krishnaiah NV, Sarma NP, Bown DP, Gatehouse JA, Reddy VD, Rao KV (2003) Transgenic indica rice resistant to sap-sucking insects. Plant Biotechnol. J. 1: 231-240

Romena AR, Heinrichs EA (1989) Wild species of rice Oryza spp. as sources of resistance to rice insects. J. Pl. Prot. Tropics 6: $213-221$
Saha P, Majumder P, Dutta I, Ray T, Roy SC, Das S (2006) Transgenic rice expressing Allium sativum leaf lectin with enhanced resistance against sap-sucking insect pests. Planta 223: $1329-1343$

Savary S, Willocquet L, Elazegui FA, Castilla NP, Teng PS (2000) Rice pest constraints in tropical Asia: quantification of yield losses due to rice pests in a range of production situations. Plant Dis. 84: 357-369

Snow AA, Pilson D, Rieseberg LH, Paulsen M, Pleskac N, Reagon MR, Wolf DE, Selbo SM (2003) A Bt transgene reduces herbivory and enhances fecundity in wild sunflowers. Ecol. Appl. 13: 279-286

Song ZP, Lu BR, Zhu YG, Chen JK (2003) Gene flow from cultivated rice to the wild species Oryza rufipogon under experimental field conditions. New Phytol. 157: 657-665

Suh HS, Sato Y, Morishima H (1997) Genetic characterization of weedy rice (Oryza sativa L.) based on morpho-physiology, isozymes and RAPD markers. Theor. Appl. Genet. 94: 316321

Tiongco ER, Flores ZM, Koganezawa H, Teng PS (1993) Inoculum sources of rice tungro viruses. Philippine Phytopathol. 29: 30-41

Wang F, Yuan Q-H, Shi L, Qian Q, Liu W-G, Kuang B-G, Zeng D-L, Liao Y-L, Cao B, Jia S-R (2006) A large-scale field study of transgene flow from cultivated rice (Oryza sativa) to common wild rice (O. rufipogon) and barnyard grass (Echinochloa crusgalli). Plant Biotech. Jour. 4: 667676

Zai WX, Chen CY, Zhu XF, Chen XW, Zhang DH, Li XB, Zhu LH (2004) Analysis of T-DNA-Xa21 loci and bacterial blight resistance effects of the transgene Xa21 in transgenic rice. Theor. Appl. Gen. 109: 534-542

Zimmerman GM, Goetz H, Mielke PW Jr (1985) Use of an improved statistical method for group comparisons to study effects of prairie fire. Ecology 66: 606-611 